\title{
A Itália e o Racismo disfarçado
}

\author{
Dario Spagnuolo *
}

\section{A Itália se revela um país racista**}

A crise econômica na Europa trouxe à tona movimentos e partidos que propagam abertamente ideias xenófobas. A começar pelo partido grego "Aurora Dourada", que chegou a pedir a separação dos estudantes estrangeiros dos nacionais e foi capaz de organizar ataques-surpresa contra os imigrantes que atuam no comércio de Atenas, até os numerosos movimentos neonazistas, sobretudo na Alemanha, Holanda e Bélgica, todos propõem a expulsão dos imigrantes, acusados de serem os principais responsáveis pela crise econômica.

Assistimos, por isso, a uma explosão de agressões de fundo racista por toda a Europa. Inclusive na Itália, a prolongada campanha política racista, levada adiante durante anos pela coalizão de extrema-direita e fomentada pela imprensa, tem produzido seus trágicos resultados.

Um dos casos recentes mais dramáticos transcorreu no dia 13 de dezembro de 2011, em Firenze, quando uma pessoa de cinquenta anos, militante da extremadireita, disparou contra um grupo de trabalhadores autônomos senegaleses, assassinando fatalmente a dois e deixando ferido um terceiro ${ }^{1}$. Infelizmente, não foi um episódio isolado. Já em 2009, o jornal La República havia denunciado a existência de uma ramificação italiana da Ku Klux Klan². Em 2012, entretanto,

* Formado em Ciências Políticas; Pós-Graduado em Desenvolvimento Internacional e Prof. no Instituto "Enrico Caruso" de Nápoles.

** Traduzido do Italiano. 
ameaças abertas ao ministro Andrea Riccardi, da Cooperação e Integração Social, chegaram através do fórum da organização neonazista Stormfront, que também publicou uma lista-suja de judeus italianos ${ }^{3}$. Em que pese a gravidade dos fatos, a Itália parece ainda distante de poder encontrar uma solução para o racismo interno.

Por muito tempo a Itália se considerou um país de acolhida. A tolerância tem sido um dos traços da imagem italiana no exterior. A suposta disponibilidade para com os estrangeiros funcionava como contraponto à representação de um país que superou a pobreza às duras penas e que estava marcado pela corrupção e pelo crime organizado. Parecia quase natural, olhando de fora, que os italianos, após décadas de emigração, manifestassem certa simpatia com relação aos novos imigrantes ou, ao menos, não repetissem as mesmas atitudes negativas das quais foram vítimas quando eles mesmos emigraram para o norte da Europa ou para as Américas (STELLA, 2002).

Uma história marcada pela emigração e pela pobreza dos camponeses difundiu a ideia que os italianos eram "brava gente", título, aliás, de um filme de Giuseppe De Santis, de 1965. Este discurso, difundido em todos os níveis pelos meios de comunicação, acabou sendo introjetado pela sociedade, e desta forma, tem representado um empecilho para o confronto aberto com os temas do racismo e da discriminação, evitados ou confrontados com relutância e, via de regra, no interior de um debate ideologizado. Do mesmo modo, o mito dos "italianos brava gente" tem alimentado uma espécie de negação, que acabou por minimizar até mesmo a responsabilidade da Itália fascista, manifestada durante a Segunda Guerra Mundial, ao lado da Alemanha nazista, autora das leis raciais (De NAPOLI, 2009).

É representativo que, diante das denúncias de atos discriminatórios e racistas, lideranças políticas tenham, por várias vezes, afirmado que "a Itália não é um país racista"; trata-se de uma atitude que esconde um modo de pensar difuso. Racismo e discriminação, na Itália, são apresentados como atos individuais e independentes do agir comportamental. Simples opiniões pessoais, desprovidas de qualquer manifestação concreta. É possível agir de modo racista e, ao mesmo tempo, declarar-se antirracista, pois, segundo uma difundida mentalidade "justificacionista", são as motivações, e não os comportamentos, que determinam uma ação como racista.

Semelhante paradoxo, tipicamente italiano, é contestado pelo filósofo e jurista Norberto Bobbio. Segundo ele, o racismo consiste em agressões verbais ou físicas que encontram motivação nas diferenças, verdadeiras ou imaginárias, entre um grupo étnico e outro, por parte de pessoas que se consideram, por razões históricas, culturais, linguísticas, superiores às demais ${ }^{4}$. 0 elemento determinante, portanto, é o comportamento, cuja gravidade não vem diminuída pela simples afirmação de motivações diversas daquelas racistas. Não é diferente a posição da União Europeia (UE) que, em matéria de discriminação, com a diretiva n. 43/2000/CE introduziu os conceitos de discriminação direta e indireta. Existe 
discriminação direta quando um indivíduo adota algum comportamento diferente em um determinado contexto (no serviço administrativo, no atendimento na área da saúde, no aluguel de uma casa, na matrícula escolar, etc.), motivado por diferenças de etnia, religião, orientação sexual, etc. A discriminação indireta, ao invés, acontece quando na igualdade de tratamento, pessoas diferentes obtêm diferentes resultados. Segundo a UE, portanto, os Estados-Membros devem se responsabilizar pela diversidade de cada um, para assegurar um efetivo exercício do direito à saúde, à moradia, à educação, com base num plano de igualdade em cada país da União Europeia. O fato da UE ter-se manifestado muitas vezes sobre as temáticas do racismo e da discriminação demonstra o quanto está difundida a ideia de que a xenofobia representa uma ameaça ao processo de integração.

A resistência para fazer frente ao racismo e à discriminação na Itália tem causado também o atraso na criação do Serviço Nacional contra as Discriminações Raciais (UNAR), requerido pela União Europeia e previsto por uma norma nacional, mas encontra-se praticamente inoperante. Da mesma forma, a Itália subscreveu com atraso a Convenção europeia sobre a participação dos estrangeiros na vida pública no âmbito local, e negou-se a assinar o capítulo $C$, o qual prevê o direito de voto dos imigrantes nas eleições municipais, direito amplamente reconhecido entre os demais países da UE .

\section{Racismo e imigração na Itália}

Escreveu Paolo Rumiz "enquanto nos Países de riqueza consolidada o africano e o asiático frequentemente evocam recordações de potência colonial, nos Países de riqueza recente, o ser humano negro evoca apenas o fantasma removido da pobreza passada" (RUMIZ, 2000). Trata-se de uma afirmação que, no caso da Itália, mostra-se verdadeira. Entretanto, a escalada xenófoba tem marcado de modo particular os últimos vinte anos, quando os migrantes passaram a chegar do leste europeu.

No início dos anos 1970, chegavam à Itália alguns milhares de refugiados políticos procedentes da América Latina, do Oriente Médio e do Chifre Africano. De um modo geral, eram vistos com simpatia por um país que, à época, vangloriava-se de contar com o maior Partido Comunista da Europa Ocidental. Apesar disso, em maio de 1979, em Roma, atearam fogo em Ali Jama, um imigrante somali, sem residência fixa, enquanto dormia num banco de praça.

Dez anos após, foi o episódio de Jerry Masslo que agitou a opinião pública. Masslo era um refugiado sul-africano que, tendo chegado à Itália, após fatos controversos, acabou sendo acolhido em Roma pela Comunidade de Santo Egídio, uma associação cristã. Após ter estudado um pouco de italiano, Masslo foi para Villa Literno para trabalhar na colheita de tomates e se alojou no "gueto", um conjunto de barracas onde dormiam, aproximadamente, 2 mil africanos. $\mathrm{Na}$ noite do dia 25 de agosto de 1989, alguns ladrões italianos se infiltraram no gueto e, durante uma tentativa de roubo, Jerry Masslo foi assassinado. Trata-se 
de um assalto que se reveste de um significado todo particular, visto que entre os trabalhadores africanos os ladrões buscavam vítimas frágeis, obrigadas a suportar toda forma de injustiça, uma vez que se encontravam privadas de qualquer proteção. Desta forma, tornou-se pública a difícil condição dos trabalhadores imigrantes na agricultura, forçados a dormir em barracas, explorados pelos chamados "gatos", agentes desonestos que oferecem trabalho à diária, exigindo pagamentos para si dos próprios trabalhadores, com frequência através de maus tratos e violências.

O caso de Jerry Masslo provocou uma onda de indignação. O velório dele foi transmitido ao vivo por vários canais de televisão nacionais e o Ministro da Justiça da época, o socialista Claudio Martelli, decidiu dar início à primeira grande regularização, através da Lei 39/1990, graças à qual milhares de trabalhadores imigrantes obtiveram um visto de residência.

Nos anos 1990, porém, de episódios isolados de racismo, passou-se a uma postura política abertamente xenófoba. A guerra nos Bálcãs e a queda do Muro de Berlim (1989) provocaram o fim da cortina de ferro que separava os países do bloco soviético e socialista da Europa Ocidental. Desde então, teve início um processo de integração em que a União Europeia passou de 15 para 27 países membros, com a entrada, entre outros, da Romênia, Bulgária, Polônia, República Checa, Eslováquia, Eslovênia, Hungria, Estônia, Letônia e Lituânia.

Nesses mesmos anos, a política interna italiana assumiu tons sempre mais ásperos e racistas. De modo todo particular, a crise da Albânia, após a morte do ditador Enver Hoxa, fez com que se erguessem vozes alarmistas acerca de uma possível invasão de imigrantes do pequeno país, separado por apenas 80 quilômetros de mar da Itália. A Albânia era uma ex-colônia italiana e o governo italiano, num primeiro momento, prometeu dar sustentação à transição democrática no pequeno Estado, posto em risco, entre outros, pelo conflito eclodido na vizinha lugoslávia. Todavia, a ajuda prometida atrasou e o próprio governo albanês encheu navios de refugiados e os enviou para a Itália. Uma vez chegados à Puglia, porém, os albaneses foram trancados no estádio de Bari e em seguida repatriados.

Foi exatamente neste período que a parlamentar do partido da Lega Norte, Irene Pivetti, solicitou que, para impedir a chegada dos grandes barcos da Albânia, o Estado italiano acionasse o Exército. E na noite de 28 de março de 1997, a Corveta italiana "Zeffiro" bateu e afundou uma embarcação de refugiados. Com o impacto, perderam a vida mais de cem albaneses, entre os quais mulheres e crianças. Foi apenas o sinal mais evidente de um clima que mudou.

Nos debates políticos televisivos, os imigrantes eram acusados de roubar o trabalho aos italianos, de praticar uma concorrência desleal no mercado de mão de obra, de serem criminosos envolvidos com o tráfico de seres humanos, com a prostituição, com o mercado da droga. Foi especialmente a Lega Norte que liderou uma campanha sem interrupção contra os imigrantes na Itália, escolhendo como principais alvos os ciganos e os muçulmanos. Afirmou Marco Colombo, 
prefeito da Lega de Sesto Calende: "o mandato eleitoral que nos foi confiado pelos cidadãos é claro: em Sesto Calende, até que nós estivermos à frente, os muçulmanos não poderão rezar em comunidade" (LA REPUBBLICA, 2010). O senador da Lega, Mario Borghezio, conhecido por sua aberta intolerância, declarou-se pronto a emprestar um porco a quem quisesse passear com ele e deixar que urinasse nos terrenos onde as comunidades imigradas muçulmanas receberam a autorização para edificar mesquitas. Borghezio sempre se distinguiu por episódios emblemáticos, como o da proposta para desinfetar os assentos dos trens nos quais tenham viajado imigrantes, ou por declarações delirantes como a do aberto alinhamento às ideias de Breivik, o terrorista norueguês que se autoproclamou antimulticulturalista e anti-islâmico ${ }^{6}$. Giancarlo Gentilini, prefeito da Lega de Treviso, chegou a invocar uma verdadeira e própria caça aos imigrantes, dizendo-se pronto a abraçar o fuzil.

Neste clima é que se multiplicaram na Itália as agressões contra os estrangeiros, envolvendo de maneira grave também a comunidade hebraica e aquela cigana. $O$ racismo, o antissemitismo e o anticiganismo que afloraram não constituem fenômeno ocasional e limitado. A agressividade se estende atingindo qualquer um que pertença às faixas socialmente mais fracas e estigmatizadas: imigrantes, deficientes, idosos, homossexuais.

Também o sul da Itália não ficou imune à onda racista. A prova mais dramática foi o ataque e o incêndio a um campo cigano, nos dias 13 e 14 de maio do ano 2008, em Nápoles. Foram os próprios moradores dos pequenos prédios vizinhos que atacaram as barracas, jogando garrafas incendiárias nos lugares onde moravam também mulheres e crianças. Surpreendentemente, as forças de segurança não intervieram contra os agressores, e o caso se concluiu com o desalojamento forçado de cerca de 300 ciganos, enquanto os representantes políticos e institucionais tentaram abafar o acontecimento. $\mathrm{Na}$ verdade, os ataques contra os campos ciganos na Itália são uma triste prática, como demonstraram episódios similares acontecidos também em Milão e Roma. A situação era tal que chegou a ser denunciada pelo European Roma Rights Center (ERRC) e pela rede europeia contra o racismo e a xenofobia (Raxen). $\mathrm{Na}$ Itália também chegaram, em diferentes ocasiões, os observadores da União Europeia, que se mostraram escandalizados pelas condições de degradação e marginalização em que vivem os ciganos.

$\mathrm{Na}$ realidade, nessas mesmas condições vivem também milhares de imigrantes que são discriminados no acesso à moradia. Numerosas enquetes mostram, de fato, que para os estrangeiros é praticado um teto de aluguel superior àquele praticado aos italianos, em instalações tão precárias que aos nacionais sequer são oferecidas. Para dormir, os imigrantes são forçados a pagar por simples vagas em beliches, em quartos coletivos superlotados por dezenas de pessoas e até mesmo a pagar para poderem ocupar edifícios decadentes (ALISEI et al., 2008). Para enfraquecer ainda mais a proteção aos imigrantes, surgiu a Lei 189/2002, que prevê o "contrato de residência". Todos os trabalhadores 
imigrantes que ficam desempregados perdem, automaticamente, o visto de residência. Não Ihes sobra nada, portanto, além da condição irregular, que os obriga a suportar qualquer abuso para evitar serem denunciados. Desta forma, crescem em todas as principais metrópoles os aglomerados de barracos e os assentamentos ilegais habitados por estrangeiros.

\section{O imigrante infrator: racismo e políticas de segurança}

A campanha xenófoba na Itália se fundamenta na equação imigraçãocriminalidade. Segundo os policy maker, as cidades italianas se encontram em perigo em virtude da chegada de pessoas provenientes de países distantes. Porém, esta opinião generalizada é desmentida pelas estatísticas.

Segundo dados do Ministério do Interior, os homicídios na Itália apresentam números inferiores aos registrados na Grécia, nos Países Baixos, em Portugal e na Finlândia. Da mesma forma, os furtos a residências são muito superiores em países tais como Reino Unido, Irlanda e França ${ }^{7}$. Pesquisa encomendada pelo Ministério de Assuntos Internos à Università Cattolica confirma que a criminalidade, de um modo geral, apresenta dados decrescentes e que não existe nenhuma correlação entre presença estrangeira e crimes cometidos ${ }^{8}$.

A imagem do imigrante infrator encontra explicação em dois fatos. 0 primeiro é o grande número de estrangeiros que se encontram detidos no sistema prisional italiano; o segundo refere-se aos meios de comunicação social. Quanto à grande presença de estrangeiros nas prisões italianas, o fato deve-se à progressiva criminalização da pobreza. Nos últimos anos, de fato, as autoridades de praticamente todas as cidades italianas baixaram normas de combate a atividades tais como: pedir esmola, limpar para-brisas nos semáforos ou remexer o lixo. Uma das consequências de tais procedimentos foi a de inflar as cifras relativas aos denunciados e aos condenados, abarrotando as prisões com lotações acima dos limites permitidos. Entre os detidos, é grande o número de imigrantes, pois são eles os únicos que podem cometer o delito da imigração irregular. Além do mais, a maior parte dos imigrantes detidos encontra-se à espera de julgamento. Entretanto, dificilmente quem é estrangeiro pode beneficiarse com a prisão domiciliar e, assim sendo, permanecem detidos durante anos, embora não se tenha nenhuma prova de que tenham cometido algum crime.

De acordo com dados do Ministério da Justiça, a população carcerária é composta por $37 \%$ de imigrantes, procedentes de mais de 150 países; desses, mais de um terço aguardam julgamento ${ }^{9}$.

É a imprensa, sobretudo, quem alimenta na opinião pública a imagem do imigrante como infrator. Pesquisa realizada em 2007 junto a dois jornais de alcance nacional e dez de âmbito local da Campania revela que, sobre doze temas selecionados, quase $60 \%$ dos artigos de jornal que falam dos imigrantes, abordam episódios relacionados à criminalidade, enquanto os $40 \%$ restantes reportam-se a temas como política, acidentes, trabalho, costumes, informações gerais, escola, esporte, saúde. 
Quando os cronistas se reportam a crimes nos quais estão envolvidos imigrantes, a pertença étnica ganha maior destaque do que o próprio ato cometido. Não se trata de ladrões, assassinos, contraventores, trata-se de magrebinos, africanos, albaneses ou extracomunitários que roubam, matam e cometem contravenções. Basta a simples suspeita para os jornalistas se sentirem autorizados a afirmar que o autor do crime é um estrangeiro. Em alguns artigos, a terminologia é selecionada com a clara intenção de ofender, pois termos como cigano, extracomunitário, marroquino já adquiriram conotação negativa.

Como se não bastasse, a própria diagramação das páginas dos jornais induz à suspeição. Em alguns casos, as matérias que abordam fatos relativos às mulheres imigrantes, aparecem nas mesmas páginas dedicadas aos anúncios referentes ao sexo e, por vezes, fica difícil distinguir se as fotografias integram o anúncio ou a matéria.

Aos imigrantes não é facultado nenhum direito de réplica, tanto assim que entrevistas com imigrantes ou artigos que trazem testemunhos de estrangeiros representam menos de $2 \%$ do total das matérias que versam, sob os mais variados títulos, sobre migrações (SPAGNUOLO, 2005). Não deve causar surpresa se, neste contexto, o associativismo entre os imigrantes é tão débil.

O destaque dado pela mídia aos crimes, comprovados ou presumíveis, cometidos por imigrantes é o estopim que desencadeia o medo em relação ao diferente e, ao mesmo tempo, as desvantagens que os imigrantes sempre levam. Os temores em relação às incertezas do futuro e à crise econômica são transformados, pelos meios de comunicação, em medo contra a própria incolumidade física. As causas do mal-estar encontram-se encarnadas no imigrante e, desta forma, oferece-se a possibilidade de uma reação fácil diante dos males existentes, instigando à violência.

Considerando o cenário atual, mesmo para um imigrante que deseja se integrar, a possibilidade dele vir a cometer um delito é enorme. Com a introdução do crime, por exemplo, de estar irregularmente no país, a Itália corre o risco de ver-se diante de outros 500 mil foragidos. Para agravar ainda mais a situação, o "decreto de segurança" de 2009 introduziu também a prisão para aqueles que, sem motivo justo, não se encontram em condições de apresentar às autoridades competentes o passaporte e o visto de permanência. Visando garantir a celeridade do processo, além de tudo, foi dada competência ao juiz de paz para todas as ações jurídicas contra os estrangeiros pegos "em flagrante delito", discriminando, de fato, os imigrantes também em matéria de proteção lega ${ }^{10}$. O decreto de segurança, além de tudo, provocou mal-estar no sistema público de serviços, impondo aos funcionários das escolas e hospitais públicos (e até mesmo aos que atuam nas agências de remessas de dinheiro), a obrigação de denunciar todos os casos de irregularidade que venham a constatar. Tratase de um procedimento que fere os direitos fundamentais da pessoa e até mesmo confronta os direitos da criança, como no caso dos estudantes filhos de imigrantes desprovidos de documentação. Uma sentença do Tribunal 
Superior, que nega aos pais imigrantes desprovidos do visto de permanência o direito de permanecer junto ao filho menor que está frequentando a escola na Itália, confirma esta tendência restritiva, em total confronto seja com o que foi sancionado pela Convenção Internacional sobre os Direitos da Criança, seja com anteriores sentenças do mesmo Tribunal e, por que não dizê-lo, com o Texto Único em matéria de imigração ${ }^{11}$.

\section{Uma oportunidade perdida}

O que aconteceu na Itália, sobretudo durante o longo período de governo de centro-direita, é extremamente preocupante. Em primeiro lugar, as decisões tomadas no campo legislativo apontam para uma inversão de tendência, contrária até mesmo aos princípios constitucionais da República Italiana e aos mecanismos de integração da União Europeia. De fato, os mecanismos de discriminação introduzidos de maneira mais ou menos explícita nas normas legais, redundaram na criação de diferentes níveis de cidadania, relegando os imigrantes a uma posição inferior em relação aos cidadãos italianos, atingindo até mesmo direitos universalmente reconhecidos, como o da reunificação familiar, o direito à instrução e à saúde.

Que se tenha jogado nos ombros dos imigrantes todo o descontentamento dos que veem o próprio emprego, a renda e o direito à assistência pública ameaçados pela sua presença, é um dado de fato. As manifestações contra os imigrantes representam um evento bastante difundido. Também a chegada de refugiados, durante a última fase da crise na Líbia, tem sido acompanhada por manifestações de cidadãos que se negavam a acolher algumas centenas de africanos em seu próprio território, a tal ponto que o Governo Monti, à época no cargo, teve que providenciar, sem muito alarde, a distribuição dos refugiados por diversos albergues do sul da Itália, onde permaneceram por mais de um ano. Além do mais, é surpreendente que, num primeiro momento, a Comissão Territorial, encarregada pelo reconhecimento do status de refugiado, tenha negado a muitos africanos procedentes do Mali a concessão do visto de permanência por motivos humanitários, exceto alguns meses após, quando a situação política no Mali conflagrou-se.

As pesquisas realizadas regularmente pela Fundação Nord Est, coordenadas pelo renomado sociólogo italiano Ilvo Diamanti, por sua vez, revelam que na Itália o medo frente aos imigrantes tem crescido mais e de maneira mais rápida do que se verifica entre os demais países europeus. Durante alguns anos, o temor ao estrangeiro foi o medo dominante entre os italianos. Os dados mais recentes, entretanto, demonstram uma inversão de tendência, quase sinalizando um despertar da opinião pública italiana. De fato, com o agravamento da crise econômica, os maiores temores passaram a ser em relação à perda do emprego, da casa, da renda, de ver-se golpeado inesperadamente pela pobreza, como de fato aconteceu a milhares de famílias italianas. Ao mesmo tempo, o medo frente 
ao estrangeiro e ao diferente tem sido claramente redimensionado (DIAMANTI e BORDIGNON, 2004). Todavia, o problema foi apenas protelado. A Itália ainda não superou o próprio racismo, pelo contrário, o governo de centro-direita introduziu no campo legislativo numerosas leis que não deixarão de ter seu peso ao longo dos próximos anos.

O que, porém, aparece com maior preocupação é a situação da sociedade italiana, aparentemente desinteressada com um real processo de integração dos imigrantes. É significativo, por exemplo, que o centro de estudos do Censis, em seu relatório anual sobre a Itália, referente ao ano de 2009, afirme que se trata de um país "teimosamente replicante", isto é, capaz de fazer frente aos acontecimentos, mas incapaz de mudar ou propor algo de novo (CENSIS, 2009).

A Itália, neste sentido, ao se enclausurar progressivamente numa postura racista e deixando à margem mais de 5 milhões de imigrantes, optou por não se valer da contribuição dos mesmos para poder superar a crise. A história das migrações ao longo do século $X X$, efetivamente, tem revelado que nos países em que foi oferecida aos imigrantes a possibilidade de integração, estes têm contribuído de modo decisivo para o crescimento econômico e social.

A Itália, pelo contrário, parece estar muito distante desta perspectiva. A atual situação de pronta discriminação diante dos imigrantes, que permeia a sociedade, parece, antes, estar semeando as bases de um conflito social crescente.

\section{Notas}

1 - Trata-se de Gianluca Casseri, militante do grupo extremista Casapound. Casseri, perseguido pela polícia, suicidou-se poucas horas após ter cometido a tragédia.

2 - La Repubblica, 1 de novembro de 2009. O artigo se refere a um blog italiano da Ku Klux Klan, no qual se encontra a história da organização racista na Itália e convite aos visitantes para se inscreverem.

3- O fórum italiano foi ofuscado pela Polícia Postal em 2012, sob acusação de encitamento ao ódio racial e antissemita.

4 - Segundo Bobbio, o racismo existe exatamente quando se explicita em atitudes que consistem na ironia das palavras, no ato de esquivar-se, na discriminação e na segregação, na agressão, podendo esta chegar ao extermínio de massa (BOBBIO, 1998, p.123-137).

5 - Conselho Europeu, Convention on the Participation of Foreigners in Public Life at Local Level, Strasburgo, 5 fevereiro 1992. O artigo 6 do Capítulo C estabelece: "Cada partido, submetido às disposições do Artigo 9, parágrafo 1, encarrega-se de garantir a todo estrangeiro residente, o direito de votar e de se apresentar como candidato para a autoridade eleitoral local, sob a condição de preencher os mesmos requisitos legais aplicáveis aos nacionais e aos demais, que sejam legítimos e habituais residentes no referido Estado, no prazo de cinco anos antes das eleições".

6 - Anders Breivik, terrorista da Noruega, autor dos atentados que em 22 de julho de 2011 provocaram, em Oslo, 70 vítimas. Durante o processo se proclamou antimulticulturalista, anti-islâmico e pró-sionista, assegurando que os atentados tinham como objetivo despertar a consciência da identidade própria do povo da Noruega.

7 - $O$ dado citado se refere ao ano de 2002. Segundo os dados do Censis, relativos a 2005, Londres é a cidade com o maior número de vítimas de crimes "urbanos", o equivalente a $32 \%$ 
da população. Em último aparecem Paris (18\%) e Roma (17\%). A percepção de insegurança, ao contrário, resulta mais elevada nas cidades mediterrâneas (Atenas, Lisboa, Marselha, Nápoles) e menos naquelas onde a qualidade de vida é maior (Helsinki, Estocolmo, Viena, Barcelona) (MINISTERO DELL'INTERNO, 2007).

8 - Trata-se da pesquisa Processi migratori e integrazione nelle periferie urbane (2009), encomendada pelo Ministério do Interior à Università Cattolica del Sacro Cuore.

9 - Os dados podem ser consultados em www.giustizia.it.

10 - Lei 15 de Julho de 2009, n. 94, “Art. 20-bis. - (Apresentação imediata a juízo do imputado em casos particulares). I. Pelos crimes que precedem do ofício, em caso de fragrante do crime ou quando a prova for evidente, a polícia judicial pede ao ministério público a autorização para apresentar imediatamente o imputado a juízo diante do juiz de paz."

11 - A propósito, o T.U. n. 286/98 em matéria de imigração no art. 31 c. 3 afirma "O tribunal para os menores de idade, por motivos graves relacionados com o desenvolvimento psicofísico e considerando a idade e as condições de saúde do menor que se encontra no território italiano, pode autorizar o ingresso ou a permanência do membro da família, por um período de tempo determinado, mesmo contrariando as demais disposições do presente texto único".

\section{Referências}

ALISEI et al (org.). Sotto la soglia. Indagine conoscitiva sul disagio abitativo degli immigrati in Italia meridionale. Ministero della Solidarietà sociale, 2008.

BOBBIO, N. Elogio della mitezza e altri scritti morali. Nuova Pratiche ed.: Milano, 1998, p. 123-137.

CENSIS. $43^{\circ}$ rapporto sulla situazione sociale del paese 2009. Angeli: Milano, 2009, p. 1 e 3.

DE NAPOLI, O. La prova della razza. Cultura giuridica e razzismo in Italia negli anni trenta. Firenze: Le Monnier, 2009.

DIAMANTI, I. e BORDIGNON, F. Allargamento e integrazione dell'Europa. Orientamenti e atteggiamenti dei cittadini europei. Quaderni della Fondazione Nord Est, n. 8 maggio 2004.

MINISTERO DELL'INTERNO. Rapporto sulla criminalità in Italia: analisi, prevenzione, contrasto. Roma, 18 giugno 2007.

RUMIZ, P. L'identità nazionale e l'alibi immigrati. In: La Repubblica, 25 agosto 2000.

SPAGNUOLO, D. L'immigrato in Campania. Immagine distorta e percezione di superficie. Glob. act Publishing: Perugia, 2005.

STELLA, G. L'Orda. Quando gli albanesi eravamo noi. Milano: Rizzoli, 2002.

\section{RESUMO}

A acolhida e a hospitalidade são consideradas uma das características próprias da identidade italiana. Nos últimos anos, contudo, gravíssimos episódios de racismo demonstraram que em relação aos imigrantes existe um clima de ameaça que pareceria ter sido agravado pela crise econômica. Não obstante isto, o problema do racismo foi redimensionado pelos policy maker e pela mídia, que são exatamente aqueles que mais se lançam contra os imigrantes, acusados de ameaçar o bem-estar e a segurança. Junto ao multiplicar-se das agressões contra os mesmos, numerosas leis criminalizaram a pobreza e empurraram a população estrangeira à margem da legalidade. Este artigo tem por objetivo explicar as razões da falha da Itália em reconhecer o problema do racismo, bem como sua falta de habilidade e falta de vontade de lidar com ele. Por quanto tempo poderá continuar esta situação antes de desembocar num aberto conflito social?

Palavras-chave: imigrantes; racismo; Itália. 


\begin{abstract}
Welcoming and hospitality are considered as an own characteristic of the Italian identity. In the last years, however, serious episodes of racism showed that, in relation to the immigrants exists a threatening atmosphere, which seems to be worsened due to the economical crisis. In spite of this, the racism problem was resized by the police makers and media, those who more against the immigrants play, accused of threatening their well being and safety. Together with the aggression against the immigrants increase, many laws criminalizing the poverty, pushing the foreign population outside towards the legality border. This article aims to explain the reasons for Italy's failure to acknowledge the racism problem, as well as its consequent inability and unwillingness for dealing with it. For how long can this situation last, before becoming an open social conflict?
\end{abstract}

Keywords: immigrants; racism; Italy. 
